OPEN ACCESS

Edited by:

Alexander A. Tarnutzer, Universität Zürich, Switzerland

Reviewed by:

Nicolas Perez-Fernandez,

Clinica Universidad de

Navarra, Spain

Jorge Kattah,

University of Illinois

College of Medicine,

United States

*Correspondence:

Luke Chen

lukechen@internode.on.net

Specialty section:

This article was submitted

to Neuro-Otology, a

section of the journal

Frontiers in Neurology

Received: 20 March 2018

Accepted: 04 April 2018

Published: 24 April 2018

Citation:

Chen L and Halmagyi GM (2018)

Central Lesions With Selective

Semicircular Canal Involvement Mimicking Bilateral Vestibulopathy.

Front. Neurol. 9:264.

doi: 10.3389/fneur.2018.00264

\section{Central Lesions With Selective Semicircular Canal Involvement Mimicking Bilateral Vestibulopathy}

\author{
Luke Chen $^{1 *}$ and G. Michael Halmagyi ${ }^{2}$ \\ ${ }^{1}$ Faculty of Medicine, University of New South Wales, Sydney, NSW, Australia, ${ }^{2}$ Neurology Department, \\ Royal Prince Alfred Hospital, Sydney, NSW, Australia
}

Bilateral vestibulopathy (BVP), which is due to peripheral lesions, may selectively involve certain semicircular canal (SCC). Recent eye movement recordings with search coil and video head impulse test (HIT) have provided insight in central lesions that can cause bilateral and selective SCC deficit mimicking BVP. Since neurological signs or ocular motor deficits maybe subtle or absent, it is critical to recognize central lesions correctly since there is prognostic and treatment implication. Acute floccular lesions cause bilateral horizontal SCC $(\mathrm{HC})$ impairment while leaving vertical SCC function unaffected. Vestibular nuclear lesions affect bilateral HC and posterior SCC (PC) function, but anterior SCC (AC) function is spared. When both eyes are recorded, medial longitudinal fasciculus lesions cause horizontal dysconjugacy in $\mathrm{HC}$ function and catch-up saccades, as well as selective deficiency of PC over AC function. Combined peripheral and central lesions may be difficult to distinguish from BVP. Anterior inferior cerebellar artery stroke causes two types of deficits: 1. ipsilateral pan-SCC deficits and contralateral $\mathrm{HC}$ deficit and 2. bilateral HC deficit with vertical SCC sparing. Metabolic disorders such as Wernicke encephalopathy characteristically involve $\mathrm{HC}$ but not AC or PC function. Gaucher disease causes uniform loss of all SCC function but with minimal horizontal catch-up saccades. Genetic cerebellar ataxias and cerebellar-ataxia neuropathy vestibular areflexia syndrome typically do not spare AC function. While video HIT does not replace the gold-standard, search coil HIT, clinicians are now able to rapidly and accurately identify specific pattern of SCC deficits, which can aid differentiation of central lesions from BVP.

Keywords: bilateral vestibulopathy, central vestibular disorders, semicircular canal, head impulse test, eye movements

\section{INTRODUCTION}

Bilateral vestibulopathy (BVP) is a chronic vestibular syndrome defined by bilaterally impaired vestibulo-ocular reflex, variably involving semicircular canal (SCC) and otolith function (1), as typically assessed by individual SCC head impulse test $(\mathrm{HIT})(2,3)$ and vestibular evoked myogenic potential (4), respectively. Peripheral lesions, such as gentamicin vestibulotoxicity, autoimmune inner ear diseases, bilateral Meniere's disease, and bilateral vestibular schwannomas are well recognized in BVP $(5,6)$. Central lesions, however, are increasingly recognized to affect SCC and otolith function bilaterally, thus potentially mimicking BVP (7-11). As neurological signs or other ocular motor finding may not be readily appreciable or rapidly evolving, it is important that central lesions are considered as a cause of BVP especially if a specific pattern of SCC involvement is apparent. Clinical or bedside HIT remains a useful screening test as no equipment is required and should be performed first before selecting patients for quantitative HIT 
such as search coil HIT (scHIT) and video HIT (vHIT). While scHIT is the gold-standard for evaluating individual SCC function (3), it is time consuming and semi-invasive, and, with the advent of modern video-oculography, rapid and reliable assessment of each SCC function is now possible in the clinic with vHIT $(12,13)$. In this review, we discuss current understanding of pattern of SCC abnormality in central lesions that can mimic BVP, drawing data from both scHIT and vHIT studies.

\section{PERIPHERAL LESIONS}

Bilateral vestibulopathy is commonly defined by bilateral symmetrical horizontal SCC (HC) deficit (14), but also VEMP impairment (15), without clinical or radiological involvement of central vestibular structures such as brainstem and cerebellum. In severe BVP, the loss of function of all six SCC is usually total if not near total, and it is usually assumed that horizontal and vertical SCC function is equally affected. However, vHIT has shown that anterior SCC (AC) function may be selectively spared compared to posterior canal (PC) function in BVP due to gentamicin vestibulotoxicity and bilateral Meniere's disease, whereas such sparing does not occur with idiopathic cases, those associated with sudden hearing loss and infection $(11,16)$. The mechanism of AC function sparing is thought to be disease specific. Isolated bilateral PC loss of function is an uncommon manifestation of BVP (17), often without an identifiable cause, and additional SCC deficits are usually unilateral rather than bilateral. Such cases would invariably be missed if only HC function is tested. Expectedly compensatory or catch-up saccade cumulative amplitude increases with decrease in SCC function so that gaze position error is minimized (14).

\section{VESTIBULAR NUCLEAR LESIONS}

Isolated vestibular nuclear stroke may be clinically indistinguishable from acute peripheral vestibulopathy (18). In two cases of isolated acute vestibular nuclear stroke mapped to the medial vestibular nucleus on MRI, scHIT revealed bilateral $\mathrm{HC}$ and PC deficit while "skipping" AC (19). As AC afferents project to both superior and medial vestibular nuclei (20), selective lesions of medial vestibular nucleus would theoretically leave ipsilesional AC function intact. It should be noted that there is significant overlap of afferents to different parts of vestibular nuclei; in particular, HC afferents project to superior vestibular nuclei too (21). Contralesional HC deficit is possibly mediated by inhibitory interneuronal adaptive process, similar to the explanation for isolated floccular lesions (22). Thus, it may be impossible to differentiate isolated vestibular nuclear stroke from BVP with scHIT or vHIT, and correct identification should rest on the finding of additional eye movement abnormalities, such as directionchanging, gaze-evoked nystagmus, or skew deviation. Fortunately, isolated vestibular nuclear stroke is rare.

\section{CEREBELLAR LESIONS}

Acute cerebellar lesions, whether unilateral or bilateral, can lead to selective moderate bilateral HC impairment sparing vertical
SCC function $(7,23)$ as recorded by scHIT. This pattern is of potential diagnostic value as AC but not both AC and PC function is spared in peripheral lesions. Isolated unilateral floccular stroke, in the territory of anterior inferior cerebellar artery (AICA), causes bilateral HC deficit, slightly worse contralesionally, but discordant caloric and sinusoidal rotational responses (22). The unusual finding of unilateral cerebellar lesions causing bilaterally impaired $\mathrm{HC}$ function is thought to be due involve ipsilateral inhibitory floccular projection on the vestibular nuclei, the inhibitory vestibular interneurons and contralateral floccular adaption. The reason for sparing of vertical SCC function is unknown, perhaps related to preferential response of floccular Purkinje cells to vertical rotation $(24,25)$. Cerebellar stroke, mainly unilateral (70\%) and involving the nodulus and uvula in the posterior inferior cerebellar artery (PICA) territory, causes mild reduction (25\%) in HC function (7), but AC and PC function is not affected (Figure 1), as measured by scHIT. This is possibly due to preference for horizontal over vertical rotation of the eye-movement sensitive neurons, which consist of $20 \%$ of the nodulus target neurons, in the vestibular nuclei (26). The mechanism for lack of vertical SCC involvement is unclear, but is theoretically related to directional property of nodular/ uvular Purkinje cells, which preferentially align with vertical SCC plane $(27,28)$. In contrast to BVP in cerebellar lesions, catch-up saccade cumulative amplitude does not necessarily correlate with SCC function. Compared to unilateral peripheral lesions, e.g., acute peripheral vestibulopathy, it is small during ipsilesional head impulses and may be larger during contralesional impulses (7). Dorsal vermal lesions can cause ipsilesional saccade hypometria (29) and the larger cumulative amplitude in cerebellar lesions might represent refixating eye movements in the face of saccade hypometria during contralesional impulses.

\section{MEDIAL LONGITUDINAL FASCICULUS (MLF) LESIONS}

Lesions of the MLF disrupt binocular horizontal eye movement and causes the clinical syndrome of internuclear ophthalmoplegia: during horizontal volitional saccades, the abducting eye overshoots the target with or without nystagmus while the adducting slows and/or undershoots (30). Both horizontal and vertical SCC function is abnormal in MLF lesions, though there are some differences between bilateral and unilateral lesions $(31,32)$. In bilateral MLF lesions, horizontal SCC deficit is characterized by dysconjugacy in gain, as measured by the ratio of eye to head velocity, between the adducting and abducting eye, mirroring the dysconjugacy in horizontal volitional saccades: gain of the adducting and abducting eyes is both reduced, but is more severely affected in the adducting eye (31). Several explanations have been put forward to account for abducting eye impairment, including additional abducens nerve or nuclear involvement (33) and impaired inhibition of antagonist medial rectus $(34,35)$. Impaired inhibition of medial rectus is unlikely to account for abducting eye impairment, since only excitatory but not inhibitory responses have been recorded when electrically stimulating the MLF (36). We have proposed another mechanism that 

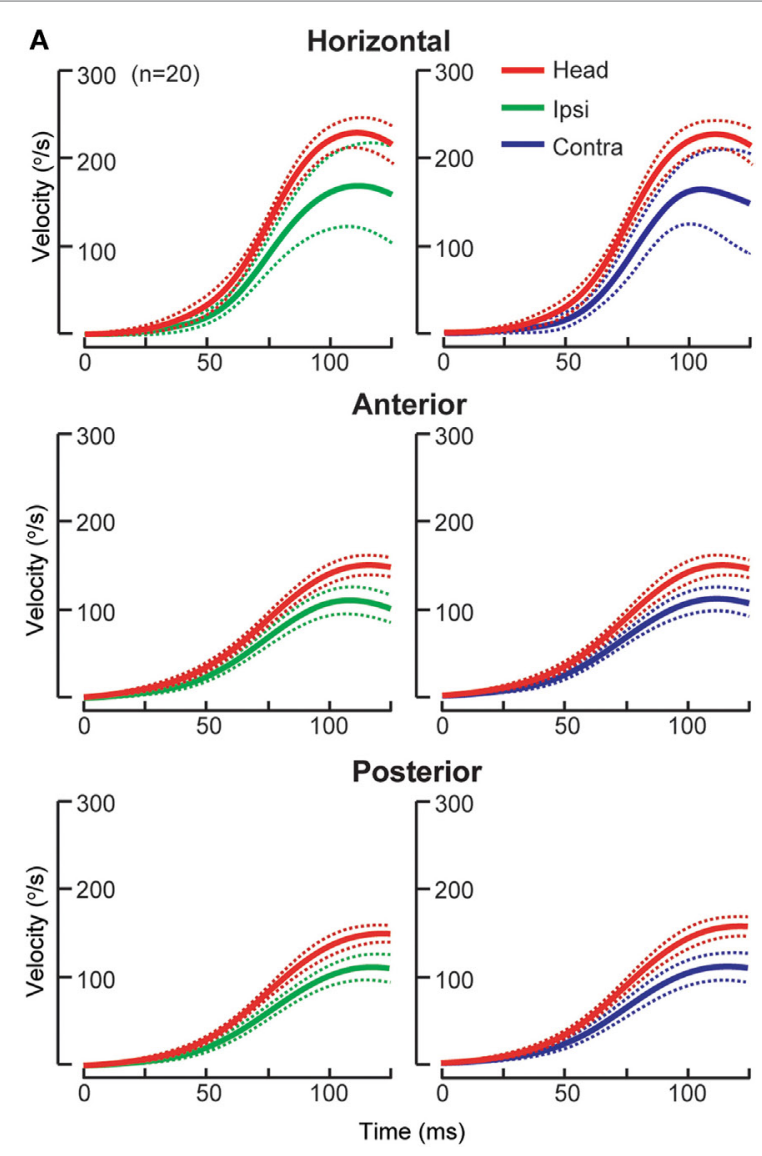

B

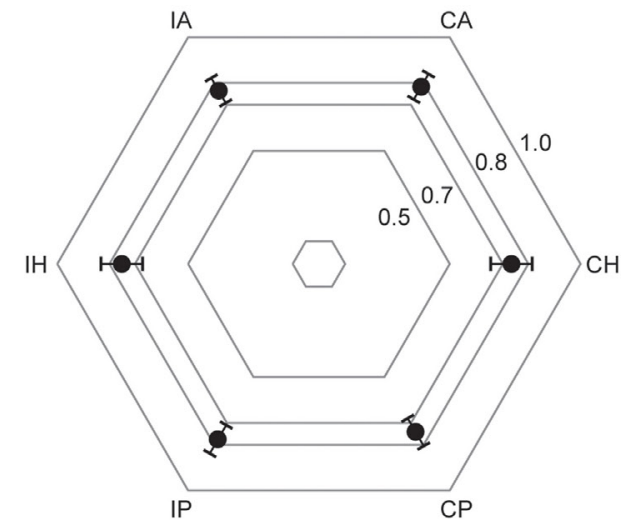

FIGURE 1 | Individual semicircular canal (SCC) function in posterior inferior cerebellar artery $(n=17)$ and superior cerebellar artery stroke (SCA, $n=3$ ). (A) Group data (mean, solid lines; 95\% confidence interval, dashed lines) displayed as time series of inverted eye and head velocities during the first $125 \mathrm{~ms}$ of head impulses, recorded using search coil HIT (sCHIT). SCC function is indicated by the gain, the ratio of eye to head velocity. There is mild bilateral $\mathrm{HC}$ impairment (gain: ipsilateral $0.75 \pm 0.09$, contralateral $0.74 \pm 0.08$ ), while both $\mathrm{AC}$ (gain: ipsilateral $0.76 \pm 0.06$, contralateral $0.78 \pm 0.06$ ) and PC function (gain: $0.77 \pm 0.06$, contralateral, $0.74 \pm 0.06$ ) is intact. Note for SCC function evoked by SCHIT, the lower limit normal for gain is $\sim 0.8$ for $\mathrm{HC}$ and $\sim 0.7$ for vertical SCC. (B) Radar plot depicting group data (mean, solid circles; 95\% confidence interval, bars) displayed as gain for each SCC. IH, ipsilesional horizontal canal; IA, ipsilesional anterior canal; CA, contralesional anterior canal; $\mathrm{CH}$, contralesional horizontal canal; $\mathrm{CP}$, contralesional posterior canal; IP, ipsilesional posterior canal. could account for abducting eye impairment in bilateral MLF lesions: during impulses toward one MLF lesion, disfacilitation of the medial rectus motoneurons of the abducting eye, which normally receives excitatory input via the abducens interneurons traveling in the opposite MLF and is inhibited by type I vestibular neurons, is defective (31). Horizontal catch-up saccades are expectedly dysconjugate, in keeping with volitional saccade dysconjugacy. However, there is discrepancy between gain and catch-up dysconjugacy: despite little or no adducting eye catch-up saccades, there is partial preservation of adducting eye gain. The ascending tract of Deiter's (37) is an extra-MLF pathway that mediates excitatory projection from vestibular nucleus to ipsilateral medial rectus motoneurons and could possibly account for the partial preservation of adducting eye gain. In unilateral MLF lesions, abducting eye gain deficit is absent, as disfacilitation of medial rectus motoneurons is intact via the unaffected contralateral MLF.

The pattern of vertical SCC deficits is similar for both bilateral and unilateral MLF lesions although the severity differs. PC contralateral to the MLF lesion is universally affected, consistent with all PC signals being transmitted via the $\operatorname{MLF}(38,39)$. AC function is relatively less affected, due to the some AC signals being relayed through extra-MLF pathways such as the brachium conjunctivum and ventral tegmental tract (3). There is less AC function sparing in bilateral MLF lesions, possibly explained by three different mechanisms: relative strength of extra-MLF pathway for AC signal (40), on-off direction asymmetry in the vertical SCC plane $(41,42)$, and property of the vertical secondary vestibular neurons such as lower resting rate (43) and higher sensitivity to rotation (44).

The clinical implication is that there is potential for misdiagnosis of MLF lesions as BVP. All vHIT devices record monocular eye movements so that it will be not possible to determine horizontal gain dysconjugacy. Some vHIT devices measure only the right eye, whereas others can be adjusted to record either eye. For right eye systems, if there is a right MLF lesion, HC function will be deficient on rightward impulses, and there will be left PC deficit with some AC sparing. This should not be confused with a patchy BVP, as left $\mathrm{HC}$ function would be intact. If there is a left MLF lesion then both HC function would be intact, and the isolated AC-PC dissociation would be diagnostic. In bilateral MLF lesions without binocular eye movement recording, it would be easy to make the mistake of diagnosing BVP, as there would be $\mathrm{HC}$ deficit (due to adducting eye deficit from one MLF lesion and abducting eye deficit from impaired disfacilitation from the other MLF lesion), and variable bilateral AC-PC dissociation. Until binocular vHIT system becomes established, it is important to examine the horizontal saccades carefully.

\section{COMBINED CENTRAL AND PERIPHERAL VESTIBULAR LESIONS}

It may be difficult to diagnose a combined central and peripheral vestibular lesion if only peripheral signs, e.g., SCC deficits consistent with BVP, or central signs, e.g., gaze-evoked nystagmus and impaired smooth pursuit are considered (45). However, 

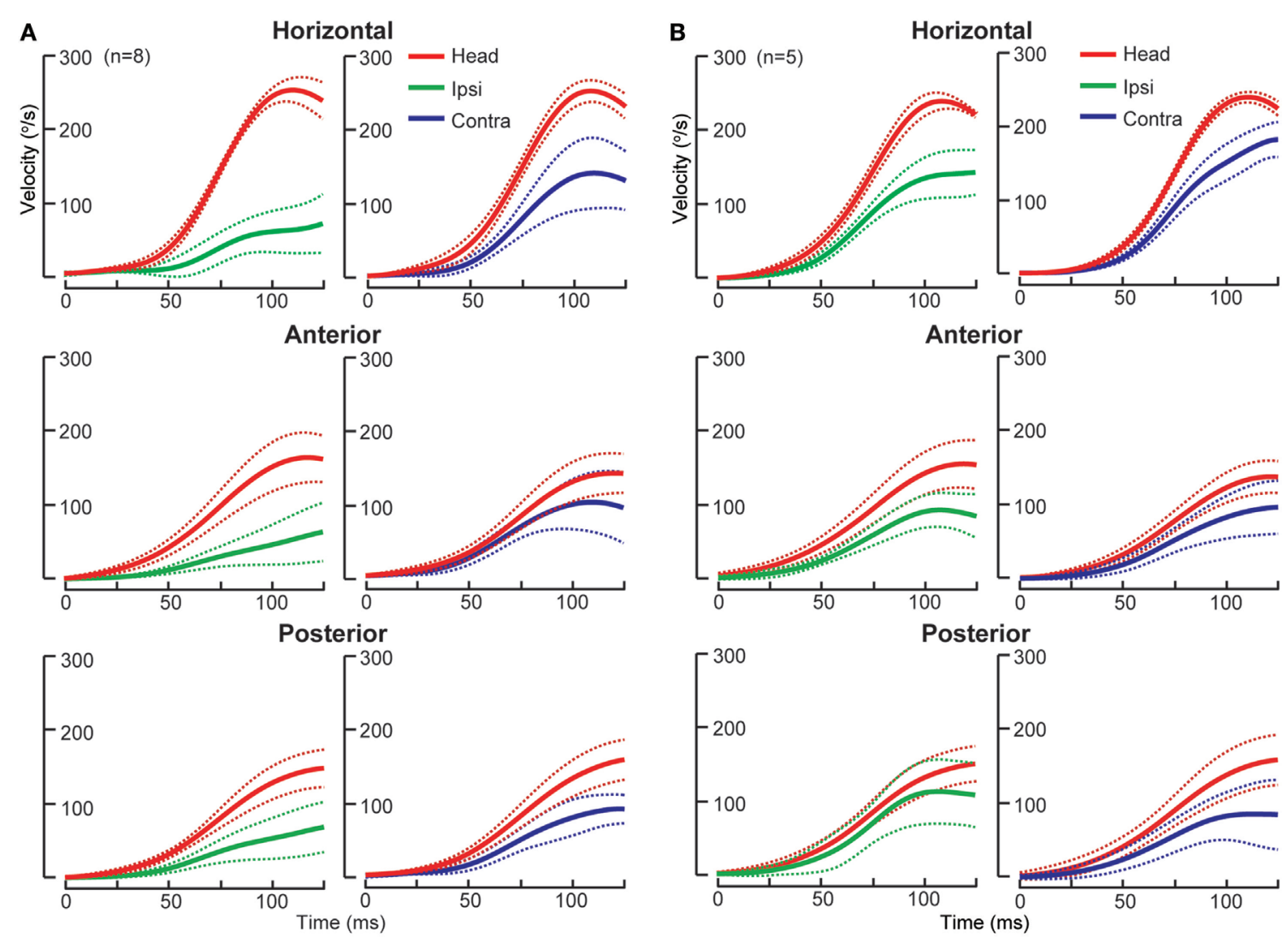

C

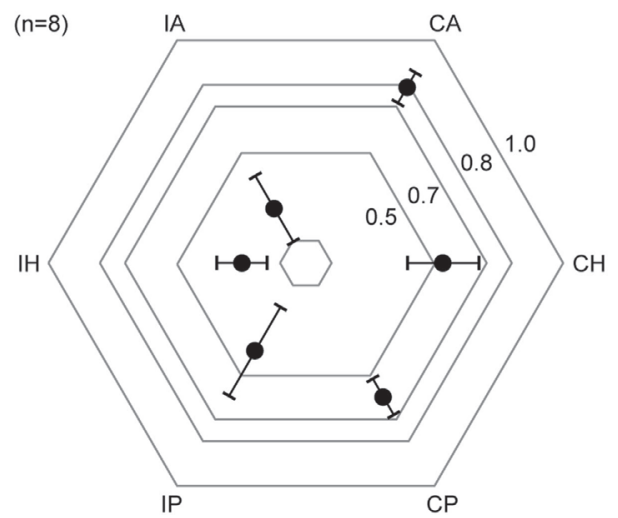

D

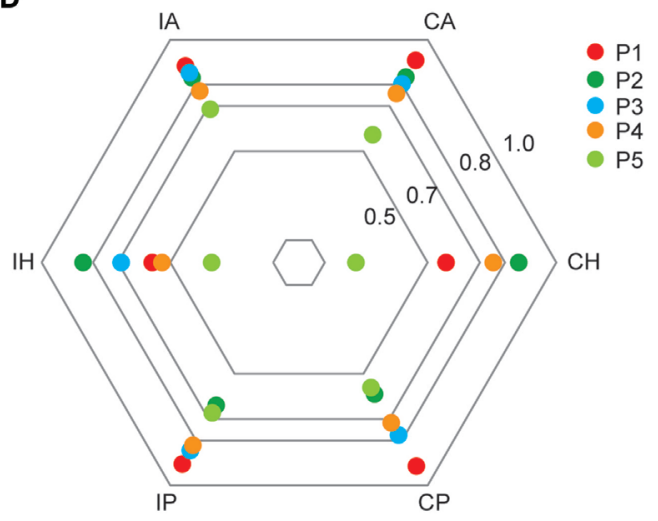

FIGURE 2 | Individual semicircular canal function in anterior inferior cerebellar artery (AICA) stroke. (A) In the first type of AICA stroke $(n=8)$, group data displayed as time series of inverted eye and head velocities during the first $125 \mathrm{~ms}$ of head impulses, recorded using search coil HIT. Ipsilesional HC (gain $0.25 \pm 0.10$ ), AC (gain $0.24 \pm 0.15$ ), and PC (gain $0.39 \pm 0.20$ ) function was deficient, while only contralesional HC (gain $0.53 \pm 0.14$ ) but not AC (gain $0.79 \pm 0.07$ ) function was impaired. Contralesional PC function (gain $0.60 \pm 0.08$ ) function was slightly reduced, probably consistent with the severe ipsilesional AC deficit and reflects the onoff direction asymmetry. (B) In the second type of AICA stroke $(n=5)$, there is mild bilateral symmetrical HC deficit while AC and PC function is preserved. Radar plots depicting mean gain $\pm 95 \%$ confidence interval for the first type of AICA stroke $(n=8)$ and individual values for the second type of AICA stroke $(n=5)$ are presented in (C,D), respectively. IH, ipsilesional horizontal canal; IA, ipsilesional anterior canal; CA, contralesional anterior canal; $\mathrm{CH}$, contralesional horizontal canal; $\mathrm{CP}$, contralesional posterior canal; IP, ipsilesional posterior canal; P, patient.

certain patterns of SCC deficits and catch-up saccade characteristic should still prove helpful. Recent studies have highlighted a number of disorders that can present with combined central and peripheral lesions: AICA strokes and cerebellopontine angle (CPA) tumor $(7,23)$, metabolic disorders such as Gaucher disease(GD) $(8,46)$ and Wernicke encephalopathy $(10,47)$, and cerebellar degeneration $(9,48,49)$. By far, over $70 \%$ are accounted for by AICA stroke and CPA tumor (45).

\section{AICA Stroke}

The AICA supplies the vestibulocochlear nerve, root entry zone, dorsolateral pons including the vestibular nuclei and flocculus (50). 
Thus, in AICA stroke, a spectrum of audiovestibular loss is expected (51). There are two patterns of SCC deficits as identified by scHIT (Figure 2), likely reflecting variable combination of peripheral and central involvement. In the first type, there are ipsilesional pan-SCC deficits, i.e., involving HC, AC, and PC, and contralesional SCC deficit involving $\mathrm{HC}$, but not AC or PC. In the second, while there is variable bilateral HC involvement, vertical SCC is not affected. While both types are characterized by unilateral lesions causing bilateral HC impairment, which is probably explained by inhibitory floccular target neurons and interneurons between vestibular nuclei $(7,22)$, in the first type, ipsilesional vertical SCC is affected, suggestive of additional involvement of vestibular end organs/primary afferents/root entry zone, whereas in the second, lack of vertical SCC involvement suggests sparing of vestibular end organs and afferents. Horizontal catch-up saccade size is smaller when compared to acute peripheral vestibulopathy, despite similar HC impairment (7); the flocculus is possibly implicated since it modulates saccades (52) and an experimental lesion causes backward postsaccadic drift (53). CPA tumors expand progressively and cause compression of the brainstem and cerebellum, resulting in variable lesion of anatomical substrates that are similarly affected by AICA stroke.

\section{Gaucher Disease}

Gaucher disease is a hereditary storage disorder due to glucocerebrosidase deficiency. Type 3 GD causes slowed saccades, more selective for horizontal than vertical (54), and vestibular impairments $(8,46)$. All SCC function is impaired, and due to saccade slowing, there is a paucity of catch-up saccades, most marked for HC. After a horizontal head impulse, the eyes may be "locked up" transiently until a resetting impulse in the opposite direction occurs. These findings may be accounted for by neuronal loss in the abducens and vestibular nuclei (55). If a patient with BVP does not consistently fixate on the center target, i.e., there would appear to be no catch-up saccade then this can potentially mimic GD. Repeated instruction to the patient and careful examination of saccade should minimize diagnostic confusion.

\section{Wernicke's Encephalopathy}

Acute Wernicke's encephalopathy (WE), due to thiamine deficiency, may not present with the classic triad of encephalopathy, ataxia, and ophthalmoplegia (56). SCC deficit is characterized by selective, symmetrical HC impairment, with sparing of the vertical SCC, as demonstrated by both scHIT (47) and vHIT (10). Presumably, the medial vestibular nucleus, which receives afferents from $\mathrm{HC}$, is particularly vulnerable to the effect of thiamine deficiency (57). Prompt recognition and treatment not only restores SCC deficit (58) but also potentially prevent permanent neurological impairment. The major differential consideration of acute WE is AICA stroke presenting isolated bilateral $\mathrm{HC}$ deficit, and MRI is likely to provide additional diagnostic clarification.

\section{Cerebellar Degeneration}

A characteristic abnormality of simultaneous cerebellar and vestibular involvement is the impaired visually enhanced vestibulo-ocular reflex (48), which may be present in certain types of cerebellar degeneration. This sign, along with gaze-evoked nystagmus, is of particular diagnostic importance as AC function sparing may not occur in cerebellar degeneration. In Friedreich's ataxia (FA), SCC function is globally reduced (9), whereas in spinocerebellar ataxia type 6 (SCA6), SCC function may be increased or decreased depending on disease severity (49). The reason for this difference is not known, but is potentially related to anatomical substrate and pathogenesis: in FA, vestibular end organs and afferents are involved, whereas in SCA6, increased function is thought to be related to initial disinhibition of deep cerebellar nuclei due to cerebellar long term depression in suppressing Purkinje cell activity and decreased in function due to later neuronal loss in the flocculus. Cerebellar ataxia, neuropathy, and vestibular areflexia syndrome (CANVAS) is a sensory ganglionopathy (59), which causes bilateral HC and vertical SCC deficits (16). Both CANVAS and FA are associated with impaired visually enhanced vestibulo-ocular reflex and bilateral SCC deficits not sparing AC function.

\section{CONCLUSION}

A number of central lesions can mimic BVP and poses diagnostic dilemma. Correct identification of central lesions is important, as both prognosis and treatment differ from BVP. In central lesions, specific patterns of SCC deficit may provide diagnostic clue and horizontal catch-up saccade size does not always correlate with SCC function. While scHIT remains the gold-standard for assessment of individual SCC function, the availability of vHIT has allowed clinicians to rapidly evaluate individual SCC function at point of care. In general, neurology practice vHIT availability is likely limited and clinical or bedside HIT remains a good screening test. Combined central and peripheral lesions are perhaps the most challenging to diagnose, and other eye movement abnormalities and MRI findings may be required to establish the diagnosis.

\section{AUTHOR CONTRIBUTIONS}

LC designed the study, analyzed eye movement data, and prepared and interpreted all the research data and figures. He was principally in charge of drafting, revising for intellectual content, and submitting the manuscript. GMH assisted in designing the study, interpreted research data figure, and in revising the manuscript for intellectual content.

\section{FUNDING}

This study was supported by the Garnett Passe and Rodney Williams Memorial Foundation and Royal Prince Alfred Hospital Neurology Department Trustees. 


\section{REFERENCES}

1. Strupp M, Kim JS, Murofushi T, Straumann D, Jen JC, Rosengren SM, et al. Bilateral vestibulopathy: diagnostic criteria consensus document of the classification committee of the Bárány society. J Vestib Res (2017) 27(4):177-89. doi:10.3233/VES-170619

2. Halmagyi GM, Curthoys IS. A clinical sign of canal paresis. Arch Neurol (1988) 45(7):737-9. doi:10.1001/archneur.1988.00520310043015

3. Cremer PD, Halmagyi GM, Aw ST, Curthoys IS, McGarvie LA, Todd MJ, et al. Semicircular canal plane head impulses detect absent function of individual semicircular canals. Brain (1998) 121(Pt 4):699-716. doi:10.1093/ brain/121.4.699

4. Rosengren SM, Welgampola MS, Colebatch JG. Vestibular evoked myogenic potentials: past, present and future. Clin Neurophysiol (2010) 121(5):636-51. doi:10.1016/j.clinph.2009.10.016

5. Zingler VC, Cnyrim C, Jahn K, Weintz E, Fernbacher J, Frenzel C, et al. Causative factors and epidemiology of bilateral vestibulopathy in 255 patients. Ann Neurol (2007) 61(6):524-32. doi:10.1002/ana.21105

6. Batuecas-Caletrio A, Yanez-Gonzalez R, Sanchez-Blanco C, Perez PB, Gonzalez-Sanchez E, Sanchez LA, et al. Glucocorticoids improve acute dizziness symptoms following acute unilateral vestibulopathy. J Neurol (2015) 262(11):2578-82. doi:10.1007/s00415-015-7918-x

7. Chen L, Todd M, Halmagyi GM, Aw S. Head impulse gain and saccade analysis in pontine-cerebellar stroke and vestibular neuritis. Neurology (2014) 83(17):1513-22. doi:10.1212/WNL.0000000000000906

8. Chen L, Halmagyi GM, Todd MJ, Aw ST. Vestibular and saccadic abnormalities in Gaucher's disease. JIMD Rep (2014) 13:111-8. doi:10.1007/8904_2013_264

9. Fahey MC, Cremer PD, Aw ST, Millist L, Todd MJ, White OB, et al. Vestibular, saccadic and fixation abnormalities in genetically confirmed Friedreich ataxia. Brain (2008) 131(Pt 4):1035-45. doi:10.1093/brain/awm323

10. Akdal G, MacDougall HG, Chen L, Tanriverdizade T, Yigitaslan O, Halmagyi GM. Selective impairment of horizontal vestibulo-ocular reflexes in acute Wernicke's encephalopathy. J Neurol Sci (2016) 365:167-8. doi:10.1016/j.jns.2016.04.013

11. Halmagyi GM, Chen L, MacDougall HG, Weber KP, McGarvie LA, Curthoys IS. The video head impulse test. Front Neurol (2017) 8:258. doi:10.3389/fneur.2017.00258

12. MacDougall HG, Weber KP, McGarvie LA, Halmagyi GM, Curthoys IS. The video head impulse test: diagnostic accuracy in peripheral vestibulopathy. Neurology (2009) 73(14):1134-41. doi:10.1212/WNL.0b013e3181bacf85

13. Macdougall HG, McGarvie LA, Halmagyi GM, Curthoys IS, Weber KP. The video head impulse test (vHIT) detects vertical semicircular canal dysfunction. PLoS One (2013) 8(4):e61488. doi:10.1371/journal.pone.0061488

14. Aw ST, Todd MJ, Aw GE, Weber KP, Halmagyi GM. Gentamicin vestibulotoxicity impairs human electrically evoked vestibulo-ocular reflex. Neuro$\log y$ (2008) 71(22):1776-82. doi:10.1212/01.wnl.0000335971.43443.d9

15. Agrawal Y, Bremova T, Kremmyda O, Strupp M. Semicircular canal, saccular and utricular function in patients with bilateral vestibulopathy: analysis based on etiology. J Neurol (2013) 260(3):876-83. doi:10.1007/s00415-012-6724-y

16. Tarnutzer AA, Bockisch CJ, Buffone E, Weiler S, Bachmann LM, Weber KP. Disease-specific sparing of the anterior semicircular canals in bilateral vestibulopathy. Clin Neurophysiol (2016) 127(8):2791-801. doi:10.1016/j. clinph.2016.05.005

17. Tarnutzer AA, Bockisch CJ, Buffone E, Weber KP. Association of posterior semicircular canal hypofunction on video-head-impulse testing with other vestibulo-cochlear deficits. Clin Neurophysiol (2017) 128(8):1532-41. doi:10.1016/j.clinph.2017.04.029

18. Kim HA, Lee H. Isolated vestibular nucleus infarction mimicking acute peripheral vestibulopathy. Stroke (2010) 41(7):1558-60. doi:10.1161/STROKEAHA. 110.582783

19. Kim HJ, Lee SH, Park JH, Choi JY, Kim JS. Isolated vestibular nuclear infarction: report of two cases and review of the literature. J Neurol (2014) 261(1):121-9. doi:10.1007/s00415-013-7139-0

20. Goldberg JM, Wilson VJ, Cullen KE, Angelaki DE, Broussard DM, ButtnerEnnever JA, et al. The Vestibular System: A Sixth Sense. New York: Oxford University Press (2012). xiii, 541 p.

21. Büttner-Ennever J. Neurochemistry of the vestibular system. In: Beitz AJ, Anderson JH, editors. Overview of the Vestibular System: Anatomy. Boca Raton: CRC Press (2000). p. 3-24.
22. Park HK, Kim JS, Strupp M, Zee DS. Isolated floccular infarction: impaired vestibular responses to horizontal head impulse. J Neurol (2013) 260(6): 1576-82. doi:10.1007/s00415-013-6837-y

23. Kim SH, Kim HJ, Kim JS. Isolated vestibular syndromes due to brainstem and cerebellar lesions. J Neurol (2017) 264(Suppl 1):63-9. doi:10.1007/s00415017-8455-6

24. Graf W, Simpson JI, Leonard CS. Spatial organization of visual messages of the rabbit's cerebellar flocculus. II. Complex and simple spike responses of Purkinje cells. J Neurophysiol (1988) 60(6):2091-121. doi:10.1152/jn.1988.60.6.2091

25. De Zeeuw CI, Wylie DR, DiGiorgi PL, Simpson JI. Projections of individual Purkinje cells of identified zones in the flocculus to the vestibular and cerebellar nuclei in the rabbit. J Comp Neurol (1994) 349(3):428-47. doi:10.1002/cne.903490308

26. Meng H, Blazquez PM, Dickman JD, Angelaki DE. Diversity of vestibular nuclei neurons targeted by cerebellar nodulus inhibition. J Physiol (2014) 592(Pt 1):171-88. doi:10.1113/jphysiol.2013.259614

27. Barmack NH, Yakhnitsa V. Cerebellar climbing fibers modulate simple spikes in Purkinje cells. JNeurosci (2003) 23(21):7904-16. doi:10.1523/ JNEUROSCI.23-21-07904.2003

28. Yakhnitsa V, Barmack NH. Antiphasic Purkinje cell responses in mouse uvula-nodulus are sensitive to static roll-tilt and topographically organized. Neuroscience (2006) 143(2):615-26. doi:10.1016/j.neuroscience.2006.08.006

29. Takagi M, Zee DS, Tamargo RJ. Effects of lesions of the oculomotor vermis on eye movements in primate: saccades. J Neurophysiol (1998) 80(4):1911-31. doi:10.1152/jn.1998.80.4.1911

30. Zee DS. Internuclear ophthalmoplegia: pathophysiology and diagnosis. Baillieres Clin Neurol (1992) 1(2):455-70.

31. Aw ST, Chen L, Todd MJ, Barnett MH, Halmagyi GM. Vestibulo-ocular reflex deficits with medial longitudinal fasciculus lesions. J Neurol (2017) 264(10):2119-29. doi:10.1007/s00415-017-8607-8

32. Choi SY, Kim HJ, Kim JS. Impaired vestibular responses in internuclear ophthalmoplegia: association and dissociation. Neurology (2017) 89(24):2476-80. doi:10.1212/WNL.0000000000004745

33. Carpenter MB, Mc MR. Disturbances of conjugate horizontal eye movements in the monkey. II. Physiological effects and anatomical degeneration resulting from lesions in the medical longitudinal fasciculus. Arch Neurol (1963) 8:347-68. doi:10.1001/archneur.1963.00460040017001

34. Pola J, Robinson DA. An explanation of eye movements seen in internuclear ophthalmoplegia. Arch Neurol (1976) 33(6):447-52. doi:10.1001/archneur.1976. 00500060053011

35. Feldon SE, Hoyt WF, Stark L. Disordered inhibition in internuclear ophthalmoplegia: analysis of eye movement recordings with computer simulations. Brain (1980) 103(1):113-37. doi:10.1093/brain/103.1.113

36. Kommerell G. Unilateral internuclear ophthalmoplegia. The lack of inhibitory involvement in medial rectus muscle activity. Invest Ophthalmol Vis Sci (1981) 21(4):592-9.

37. Highstein SM, Reisine H. The ascending tract of Deiters' and horizontal gaze. Ann N Y Acad Sci (1981) 374:102-11. doi:10.1111/j.1749-6632.1981. tb30864.x

38. Uchino Y, Hirai N, Suzuki S, Watanabe S. Properties of secondary vestibular neurons fired by stimulation of ampullary nerve of the vertical, anterior or posterior, semicircular canals in the cat. Brain Res (1981) 223(2):273-86. doi:10.1016/0006-8993(81)91141-0

39. Iwamoto Y, Kitama T, Yoshida K. Vertical eye movement-related secondary vestibular neurons ascending in medial longitudinal fasciculus in cat I. Firing properties and projection pathways. J Neurophysiol (1990) 63(4):902-17. doi:10.1152/jn.1990.63.4.918

40. Mitsacos A, Reisine H, Highstein SM. The superior vestibular nucleus: an intracellular HRP study in the cat. I. Vestibulo-ocular neurons. J Comp Neurol (1983) 215(1):78-91. doi:10.1002/cne.902150108

41. Chubb MC, Fuchs AF, Scudder CA. Neuron activity in monkey vestibular nuclei during vertical vestibular stimulation and eye movements. J Neurophysiol (1984) 52(4):724-42. doi:10.1152/jn.1984.52.4.724

42. Tomlinson RD, Robinson DA. Signals in vestibular nucleus mediating vertical eye movements in the monkey. J Neurophysiol (1984) 51(6):1121-36. doi:10.1152/jn.1984.51.6.1121

43. Reisine H, Raphan T. Neural basis for eye velocity generation in the vestibular nuclei of alert monkeys during off-vertical axis rotation. Exp Brain Res (1992) 92(2):209-26. doi:10.1007/BF00227966 
44. Shimazu H, Precht W. Tonic and kinetic responses of cat's vestibular neurons to horizontal angular acceleration. JNeurophysiol (1965) 28(6):991-1013. doi:10.1152/jn.1965.28.6.991

45. Choi SY, Kim HJ, Kim JS. Chasing dizzy chimera: diagnosis of combined peripheral and central vestibulopathy. JNeurol Sci (2016) 371:69-78. doi:10.1016/j.jns.2016.09.063

46. Bremova-Ertl T, Schiffmann R, Patterson MC, Belmatoug N, Billette de Villemeur T, Bardins $\mathrm{S}$, et al. Oculomotor and vestibular findings in Gaucher disease type 3 and their correlation with neurological findings. Front Neurol (2017) 8:711. doi:10.3389/fneur.2017.00711

47. Choi KD, Oh SY, Kim HJ, Kim JS. The vestibulo-ocular reflexes during head impulse in Wernicke's encephalopathy. J Neurol Neurosurg Psychiatry (2007) 78(10):1161-2. doi:10.1136/jnnp.2007.121061

48. Migliaccio AA, Halmagyi GM, McGarvie LA, Cremer PD. Cerebellar ataxia with bilateral vestibulopathy: description of a syndrome and its characteristic clinical sign. Brain (2004) 127(Pt 2):280-93. doi:10.1093/brain/ awh030

49. Huh YE, Kim JS, Kim HJ, Park SH, Jeon BS, Kim JM, et al. Vestibular performance during high-acceleration stimuli correlates with clinical decline in SCA6. Cerebellum (2015) 14(3):284-91. doi:10.1007/s12311-015-0650-3

50. Oas JG, Baloh RW. Vertigo and the anterior inferior cerebellar artery syndrome. Neurology (1992) 42(12):2274-9. doi:10.1212/WNL.42.12.2274

51. Lee H, Kim JS, Chung EJ, Yi HA, Chung IS, Lee SR, et al. Infarction in the territory of anterior inferior cerebellar artery: spectrum of audiovestibular loss. Stroke (2009) 40(12):3745-51. doi:10.1161/STROKEAHA.109.564682

52. Noda H, Suzuki DA. The role of the flocculus of the monkey in saccadic eye movements. J Physiol (1979) 294:317-34. doi:10.1113/jphysiol.1979. sp012934

53. Zee DS, Yamazaki A, Butler PH, Gucer G. Effects of ablation of flocculus and paraflocculus of eye movements in primate. J Neurophysiol (1981) 46(4): 878-99. doi:10.1152/jn.1981.46.4.878
54. Benko W, Ries M, Wiggs EA, Brady RO, Schiffmann R, Fitzgibbon EJ. The saccadic and neurological deficits in type 3 Gaucher disease. PLoS One (2011) 6(7):e22410. doi:10.1371/journal.pone.0022410

55. Winkelman MD, Banker BQ, Victor M, Moser HW. Non-infantile neuronopathic Gaucher's disease: a clinicopathologic study. Neurology (1983) 33(8): 994-1008. doi:10.1212/WNL.33.8.994

56. Sechi G, Serra A. Wernicke's encephalopathy: new clinical settings and recent advances in diagnosis and management. Lancet Neurol (2007) 6(5): 442-55. doi:10.1016/S1474-4422(07)70104-7

57. Kattah JC, Guede C, Hassanzadeh B. The medial vestibular nuclei, a vulnerable target in thiamine deficiency. J Neurol (2018) 265(1):213-5. doi:10.1007/ s00415-017-8670-1

58. Kattah JC, Dhanani SS, Pula JH, Mantokoudis G, Tehrani ASS, Toker DEN. Vestibular signs of thiamine deficiency during the early phase of suspected Wernicke encephalopathy. Neurol Clin Pract (2013) 3(6):460-8. doi:10.1212/ WNL.0000000000005206

59. Szmulewicz DJ, McLean CA, Rodriguez ML, Chancellor AM, Mossman S, Lamont D, et al. Dorsal root ganglionopathy is responsible for the sensory impairment in CANVAS. Neurology (2014) 82(16):1410-5. doi:10.1212/ WNL.0000000000000352

Conflict of Interest Statement: LC reports no disclosures. GH is an unpaid consultant to GN Otometrics, Taastrup, Denmark, but has received support from GN Otometrics for travel and attendance at conferences and workshops.

Copyright (c) 2018 Chen and Halmagyi. This is an open-access article distributed under the terms of the Creative Commons Attribution License (CC BY). The use, distribution or reproduction in other forums is permitted, provided the original author(s) and the copyright owner are credited and that the original publication in this journal is cited, in accordance with accepted academic practice. No use, distribution or reproduction is permitted which does not comply with these terms. 